\title{
Exploring the Use of an Online Community in Welfare Transition Programs
}

\author{
Nathalie Colineau and Cécile Paris \\ CSIRO - ICT Centre \\ PO Box76, Epping NSW 1710 \\ Australia \\ firstname.lastname@csiro.au
}

\author{
Amanda Dennett \\ Media \& Network Communication Branch \\ Human Services Portfolio Communication Division \\ Tuggeranong Office Park, Canberra \\ Australia \\ amanda.dennett@centrelink.gov.au
}

\begin{abstract}
We present here the results of an initial consultation we conducted through group interviews with welfare recipients about the usefulness of establishing a government-mediated online community that would help them in making the transition from welfare support to work.
\end{abstract}

Welfare, Families, Social Support, Online Community

\section{INTRODUCTION}

As the use of the Internet is rising, an increasing number of people interact online through a variety of social media applications. More than $80 \%$ of Australians who have online access read opinions about products and services via blogs, forums and websites, $56 \%$ use social networking sites, $25 \%$ report belonging to an online community, and $42 \%$ and $14 \%$ read and write blogs respectively. ${ }^{1}$ Leveraging off the benefits such media tools can provide to reach communities, many government agencies have begun actively increasing their online presence to engage more with citizens. They use Twitter and Facebook to keep the public informed, release data sets that can then be used in mash up projects, and involve citizens in policy developments through online consultations.

While this engagement to date has been mostly focused on information (e.g., dissemination, sharing and feedback), its potential social dimension has largely been ignored. A government could also go further in its use of web 2.0 technologies by taking a mediation role, facilitating the creation of online communities for specific groups of citizens, thereby capitalising on the potential power of such communities to provide social and emotional peer-support. Is this a role that the government should take? Would this be useful for citizens? These are the issues we are exploring in this work.

Our aim is to help people currently receiving welfare payments find a job and become financially self-sufficient. The purpose is not to replace but to

${ }^{1}$ Source: Sensis e-Business Report 2010. complement existing welfare transition programmes, providing an additional channel to deliver social services. In particular, working with Centrelink (the Australian Government's service delivery agency), we are focusing on parents currently in receipt of Parenting Payment (income support to help with the costs of caring for children) who will be transitioned to Newstart Allowance (financial support while someone is looking for work). This transition occurs when their youngest child turns six or eight years old.

In this paper, we first provide some background information on welfare programs in Australia. Then, we present the results of several group interviews we conducted to 1) understand the issues this particular group of income support recipients are facing and 2) explore the idea of using an online community, facilitated by Centrelink, as a support group for them. In particular, we were interested in assessing people's level of interest and willingness to interact with the government on welfare issues.

\section{WELFARE TO WORK REFORM}

As in many developed countries, Australia offers welfare programs that provide an income support payment for people with low or no income who have the responsibility to care for one or more children. In recent years, welfare systems have changed (e.g., TANF legislation in the $U^{2}$ or the Work for the Dole program in Australia ${ }^{3}$ ). The

\footnotetext{
2 TANF: Temporary Assistance for Needy Families (see TANF program, 1997).

${ }^{3}$ See Work for the Dole Legislation, 1997.
} 
financial assistance that people used to received as entitlements is now provided in exchange of work (or some form of community participation) and offered for a limited period of time. The group we are targeting in this work has been directly affected by this reform.

The reform is based on mutual obligation requirements, whose basic tenets are:

- Welfare support is not an entitlement but a contract with obligations. If people have the capacity and availability to work, it is considered fair and reasonable to ask them to look for work in return for their benefit.

- People will be better off by being actively engaged both economically and socially in our society. The assumption here is that paid work will bring higher income and improve one's self-esteem and confidence.

- People's attitudes need to be changed. Some people are too selective in their approach to job seeking. This was often attributed to "passive welfare, poor work ethic, low motivation and excessive expectations" (Sawer, 2006; p.5).

The government's goal is to reduce the level and incidence of welfare dependence and increase participation, with a balance of assistance, incentives and obligations (Hansard, 2005; p. 2-8).

\subsection{Programme Evaluations}

The reform was presented as fair and reasonable and represented to some extent the sentiment of the community. In a study reporting on the appropriateness and effectiveness of welfare program changes between 2000 and 2005 (The Social Research Centre, 2005), $77 \%$ of the general community agreed that support should be available as long as required, while $75 \%$ also supported the idea that it should be conditional on people looking for work. There was, however, a change in attitude in the community with more people thinking it was not entirely the individual's responsibility to find a job and believing that more support was needed for unemployed people to return to work. The expectation for participation varied according to the targeted group of income support recipients. Similarly, while the community supported that sanctions be applied to enforce compliance, there was more support for the sanctions to be applied to younger unemployed (73\%) than to mature age job seekers $(35 \%)$, parents $(40 \%)$ or people with disabilities $(20 \%)$. These studies show that the citizen community at large realises that the transition is not an easy process, that people do need help and support, and that different groups may have different needs.

Early studies evaluating the impact of participation requirements on unemployed (Sawer, 2006), and female sole parent (e.g., Cameron, 2006 and Cox and Priest, 2008) recipients of income support failed to show any financial gain, or significant improvements in job prospects, while warning that the requirements could potentially put stress on family relationships. These evaluations also point to the fact that the transition can be difficult, and thus people need help. Our work investigates whether online communities can provide additional support.

\subsection{Support for Welfare Recipients}

Current support for welfare recipients to help them transition into work includes face to face community group meetings and job support networks. To the best of our knowledge, there are currently no online communities whose purpose is to support welfare recipients in their transition to work. There are a number of existing online communities and forums in which, sometimes, welfare issues are discussed and members support each other with respect to these issues. For example, Bub Hub (www.bubhub. com.au) is a portal where parents and parents-tobe can get advice and talk about their pregnancy, birth and parenting journey, and the Single Mother Forum (www.singlemother.forum.com) is specifically for Australian single mums. We are interested in having an online community that specifically addresses the needs of our target group, and explore whether a government-mediated one could be a means for different types of interactions between government and citizens.

\section{OUR WORK}

As mentioned above, we focus on families in receipt of Parenting Payment (paid either to the primary carer in a couple family or to single parents) who will be transitioned to Newstart Allowance and have new compulsory participation requirements when their youngest child turns six years old or eight years old respectively. This change process can have significant financial and emotional impacts for parents, and our aim is to explore ways to make this transition onto a new payment, and then back into the workforce, smoother and less stressful for families by setting up an online community to provide a range of support mechanisms. This would provide an additional and complementary mechanism to support this cohort.

\section{METHOD}

Our first step was to gain an understanding of the type of assistance (e.g., emotional, financial and/or informational) that would be useful for families during this transition process. We also wanted to assess whether the idea of having a social network environment as a support mechanism would be 
well received, in particular, a community mediated by the government. Finally, we wanted to hear about peoples' feelings about the government exploring new ways of supporting them and providing information.

The data was collected through group interviews and completed by an online survey to reach a larger number of people and confirm the initial findings uncovered during the interviews. The survey data is currently being analysed; therefore we present here the key points discussed during the group interviews.

\subsection{Participants}

The people who were invited to participate in the group interviews are parents who receive Parenting Payment and are transitioning to Newstart Allowance with the mandatory participation requirements to either look for work, or engage in some form of activity to assist them with re-entering the workforce. Due to the sensitivity of the information being discussed, but more importantly, the dependant relationship between the recruited participants and the government agency responsible for their payments, the group interviews were organised and facilitated by the Centrelink Concept Lab, an entity independent from any specific group or services within Centrelink. Similarly, the online survey was conducted as a „double blind' process.

Four group interviews were organised in November 2010 in two major metropolitan areas. Participants were recruited from Centrelink's customer database to ensure we reached the targeted audience. For privacy reasons, we did not have access to the details of demographics information.

Each interview was scheduled for one and a half hours. Six to eight participants were invited for each of them. Participants were given a cash reward of $A \$ 80$ as a token of appreciation for their time and feedback. A total of 25 participants were recruited and, out of those, 17 attended, with 15 participants still receiving Parenting Payment and about to be transitioned and two participants who had recently made the transition to Newstart Allowance. The majority of participants are mothers, only two participants are fathers.

\subsection{Discussion points}

In collaboration with Centrelink, we developed discussion points related to peoples' understanding of the process. These included: whether participants had received relevant and timely information about the required transition process; questions related to peoples' attitudes and feelings about their requirement to return to the workforce; questions about the social barriers they may perceive as affecting their ability to participate; questions about having to report to the government; finally, questions to gauge participants' reactions to the idea of having a social network environment as a support mechanism. In the interviews, the discussion points were explored through open conversations driven by a facilitator. In addition to the discussion questions, we had two activities in which the participants were asked to write down on post-it notes a word that described and encompassed their feelings towards looking for work and the personal factors they identified as obstacles to finding employment. These were in turn used as discussion starting points.

\section{KEY FINDINGS}

\subsection{Understanding the process}

For many this transition comes as a surprise. There was no clear understanding of what was going to happen next, what was expected from them (beyond the broad requirement to have to look for work) or what would be the consequences for them, both financially and in terms of family life organisation.

"I am unclear about the process [...]. The lack of
communication is the biggest issue [...] how
does the whole process work? [...] I am in the
dark" "
"I did not know anything about the
consequences or the requirements"

This lack of understanding made the participants feel anxious, scared and somewhat daunted. They felt lost as to what they had to do, how to start and, at the same time, overwhelmed at the number of things they would need to fit in their day.

\subsection{Attitude towards the obligation to participate}

The requirement to work was usually accepted and understood. People wanted to work or be involved in part-time activities. However, they felt that the timing was not right and that children aged six or eight still needed their parents. They were worried that the requirement to work would impact on their parenting role.

\begin{abstract}
"Why do we cease to be parents when our children turn eight? We are still parents; we still have the same exact life we had when they were seven years and 364 days old"
\end{abstract}

As a result, the requirement to participate, which was built as an incentive to move people out of welfare into the work place, was perceived as a punitive measure.

\footnotetext{
${ }^{4}$ All quotes are from participants in the group interviews.
} 
"Why has the government punished us by making us go into a system that really doesn't fit our needs?"

\subsection{Attitude towards having to look for work}

When asked to write down how they felt about looking for work, many said that they were not equipped to look for a job, mostly because they had been out of the workforce for many years. They felt that they required more support from the government than they were getting to enable them to find jobs.

\begin{abstract}
"We need to be transitioned; not just popped [...] we need help to get back to into the workforce. Right now, we only have pressure. Support us. We feel like criminals"

"I want to be trained [...] the government should take that responsibility"
\end{abstract}

This was aligned with findings reported in a study on the community's perception about welfare programs (The Social Research Centre, 2005), where fewer people in the community felt it was entirely the individual's responsibility to find work (from $63 \%$ in 2000 down to $49 \%$ in 2004), and where an increasing number of people believed that more needed to be done to help unemployed people find a job (from $74 \%$ in 2000 up to $79 \%$ in 2004).

Most participants expressed the desire to find appropriate employment (and matching their qualifications, if they had any). They were not ready to accept any job. This issue has been identified in the past as a potential problem with the requirement for participation, with people feeling pressured to accept any job as opposed to the right job for them. The requirement for participation by opposition to voluntary work corners people in precarious and low-paid jobs instead of encouraging people to engage "productively and meaningfully in the labour market" (John Falzon; cited in Cameron, 2006).

\subsection{Barriers to returning to work}

The majority of participants mentioned the difficulty of finding work with flexible hours (to match school hours of $10 \mathrm{am}$ to $2 \mathrm{pm}$ ), or a "parent-friendly" work environment able to accommodate needs such as time off during school holiday and providing paid sick leave. They also mentioned that they were really concerned about the availability and cost of childcare, and expressed the view that there was not much point in working if all the earnings would simply serve at paying child care.

"Where is my incentive to do that?"

Lack of work experience was another common theme, with people feeling "intimidated" and "out of touch", as they had been out of the work force for many years. Some also acknowledged going through relationships breakdowns and, as a result, experiencing many personal challenges on different levels.

\subsection{Attitude towards having to report to the government}

The transition to the Newstart Allowance requires reporting to the government on a regular basis. This is in sharp contrast to the Parenting Payment programme, during which people automatically receive their benefit on a fortnightly basis and have little contact with Centrelink. Most participants disliked the idea of having to come regularly into the government offices. One of the reasons was that there was a stigma associated with going into a Centrelink office and lining up to receive the "dole".

"I felt out of place. First time I am in this situation. I came out of the interview very depressed, I feel that there is a social stigma."

There were also issues of long queues and waiting times, with suggestions of online reporting options for parents (a service that has recently been introduced by Centrelink).

\subsection{Usefulness of an online community for parents}

One of our objectives was to gauge the participants' reactions towards the concept of an online community to support them through the transition process. This idea was introduced as part of the discussion points, and numerous examples were provided to explain the concept and its potential relevance to the issues and barriers identified by the participants.

Attitudes and opinions towards the idea varied at different stages of the interviews, mostly as a result of increased understanding about the concept itself, its purpose, the motivation behind it and its relationship with the current legislation. For some of the participants, it was at first extremely difficult to grasp the idea and relevance of having access to an online support network in relation with a government programme. Other participants were able to immediately see the value in it and claimed that they would indeed use it for various functions. By the end of the sessions, most participants demonstrated that they had a good understanding of the multiple purposes an online community could serve and that they would be willing to try it. From someone who had already transitioned:

\footnotetext{
"excellent idea - I wish there had been one [when I transitioned]".
} 
They thought the idea of logging under an anonymous name was appropriate, as it may foster more honest and frank discussions. Participants liked the idea of having a place where they could get relevant information, but raised concerns about wrong information being disseminated.

\begin{abstract}
"What if people shared legislative or policy advice which wasn't correct and then were penalised by Centrelink? I really think [Centrelink] should monitor the platform and correct any of those discussions if necessary"

"I like the idea of this being available. I might not want to contribute to the discussions but I would be interested in reading the information and online conversations".
\end{abstract}

Participants also raised a concern that the community would be used mostly to vent about the government or legislation, and strongly recommended that the site be monitored.

"Make it feel positive. Keep it positive"

Finally, participants liked the idea of the online community providing a mentor/buddy system. In particular, those who had already made the transition stated that it would have been an invaluable service.

\section{"It would be beneficial to everyone because it is an unknown. Someone who has already gone through it can help"}

"It would help to have old timers, like Tim [another participant], explain to people like me"

"It would be useful to access people in similar situations"

Interestingly, we observed in all the group interviews that the participants really enjoyed the dynamics of a group environment and mentioned that they found it cathartic to congregate with peers and share personal experiences. During the interviews, we saw participants share tips and ideas. This is encouraging for an online community, as this would indeed be one of its purposes.

\subsection{A community mediated by Centrelink}

Our final set of questions was about the participants' feeling about the government, and Centrelink in particular, exploring new ways of supporting them and providing information. Feedback was very positive. Although some participants had, at times throughout the sessions, been somewhat pessimistic towards the concept of providing an online community, every single individual appreciated a government agency making noticeable effort to adapt to new technology and trying to improve the available services.
"This is a positive thing"

"Good the government is exploring new ways"

"Good to exploit technologies"

Finally, they also all relished the fact that they had been contacted to attend a group interview and make a contribution.

\section{WHAT DID WE LEARN?}

The aim of the group interviews (and, later, the survey) was to inform the design and functionality of the planned online community, in particular the types of content to be provided, the people to involve and the rules to put in place.

We learnt a number of important points. As with many other online communities, users should remain anonymous to foster honest discussions and protect individuals' privacy. However, we note that this may limit Centrelink's ability to answer in any specific detail the customers' questions online. We need to clearly explain the community purpose upfront, to ensure people do not view it with suspicion, but rather as a novel means to support them through this potentially difficult transition and as an opportunity to get emotional support from peers. The community could be a place for Centrelink, and community members, to share content relevant to this customer group, thus enabling people to obtain information without searching on the agency's general website. We have identified a range of useful content that could be included (e.g., a clear fact sheet about the process; pointers to information on writing a CV), and a number of "activities" to help people go through the process (e.g., an activity in which people would be encouraged to think about their current skills).

The site must be monitored, and government officials need to check that all information is correct. Appropriate legal disclaimers also need to be clearly provided. Participants should include people on Parental Payments to be transitioned to Newstart Allowance as well as people who have already made the transition, so as to enable a mentor system. People on Parental Payments should be invited to join the community much ahead of their required transition to ensure they are equipped with the necessary knowledge in a timely fashion. The community should encourage (or may be even enforce) a buddy and/or mentor system.

\section{CONCLUSION AND DISCUSSION}

We present here the results of an initial consultation we conducted through group interviews with welfare recipients about the usefulness of establishing an online community 
facilitated by the government to help them in making the transition from welfare support to work. Our initial findings show that people need help: they need to be better informed as to what to expect and be shown some understanding through social support to successfully make this transition. The findings also suggest that people would welcome the peer-support they would get from an online community, and that they appreciate that the government is exploring new channels to support them.

Our next step is to finalise the survey analysis and implement the community, based on the requirements gathered from the group interviews and the survey.

We realise that not everyone will be able to have an online engagement with the government: for example, people might not have access to a computer or the internet, or lack the skills required to be an active online participant. At this stage, we are first trying to establish the usefulness of such an online community to support citizens. If citizens were to find this means useful, we would then look at how to make it as inclusive as possible.

In addition, we are aware that people might not wish to engage with the government online. The proposed online community is not meant to replace existing mechanisms, but rather it is meant to be an additional and complementary communication channel.

\section{ACKNOWLEDGEMENTS}

This research has been funded under the CSIROCentrelink Human Services Delivery Research Alliance (HSDRA). We would like to thank the Centrelink Concept Lab for organising and facilitating the focus groups, and all the participants for their feedback.

\section{REFERENCES}

Cameron H. (2006). Single parent family under welfare-to-work. In Proceedings of the Road to Where? The Politics and Practice of Welfare to Work Conference, School of Social Work and Applied Human Sciences, University of Queensland. 17-18 July, 2006, Brisbane.

Cox, E. and Priest, T. (2008). Welfare to Work: At What Cost To Parenting? Report available at: http://www.women.nsw.gov.au/women and work/p artnership projects/welfare to work (retrieved Dec 15, 2010)

Hansard (2005). House of Representatives, second readings by Kevin Andrews, Nov 9, 2005 Canberra: Australian Commonwealth Government.

Sawer, H. (2006). One fundamental value: work for the dole participants' views about work and mutual obligation. In Proceedings of the Road to Where? The Politics and Practice of Welfare to Work Conference, School of Social Work and Applied Human Sciences, University of Queensland. 17-18 July, 2006, Brisbane.

Sensis e-Business Report September 2010 http://about.sensis.com.au/small-business/sensisebusiness-report/ (retrieved Jan 4, 2011)

TANF program 1997 http://www.acf.hhs.gov/pro grams/ofa/tanf/about.html (retrieved Jan 6, 2011)

The Social Research Centre (2005). Customer and community attitudes to working age participation requirements. http://www.workplace.gov.au/work place/Publications/ProgrammeEvaluation/Australia nsWorkingTogetherTheConsultantsReportsFebruar y2006.htm (retrieved Dec 15, 2010)

Work for the Dole (Legislation introduced to Parliament 1997) http://www.aph.gov.au/library/ intquide/sp/dole.htm (retrieved Jan 6, 2011) 